\title{
The Micrograph Image of Early Experimental Dental Caries in Permanent Teeth
}

\author{
Vo Truong Nhu Ngoc ${ }^{1}$, Truong Manh Dung ${ }^{1}$, Le Quynh Anh ${ }^{1}$, Pham Thi Hong Thuy ${ }^{2}$, Tran \\ Tuan Anh ${ }^{3}$
}

${ }^{1}$ School of Odonto Stomatology, Hanoi Medical University, Hanoi 10000, Vietnam

${ }^{2}$ Hai Phong Medical University, Haiphong, Vietnam

${ }^{3}$ Binh Duong Medical College, Thu Dau Mot, Vietnam

Correspondencee-mail to: quynhanh0191@gmail.com

\begin{abstract}
Study on the structure and the mechanism of the formation of early caries is an important premise for evaluating the caries-preventive methods. Objective: To describe micrograph images of experimental carious lesions at early stage in permanent teeth in Vietnamese. Methods: There were 60 permanent extracted premolars from patients aged 18-25 used in this study. After cleaning and removing the remaining soft tissue, each tooth was painted with acid-resistant coating leaving an enamel window of approximately $1 \times 1 \mathrm{~mm}^{2}$ on the buccal surface. The artificial carious lesion was performed by soaking the teeth for 96 hours in the demineralization solution and evaluated using the ICDAS criteria. The tooth specimen was observed under a scanning electronic microscope (SEM). Results: The experiment resulted $66.7 \%$ of ICDAS 1 and 33.3\% ICDAS 2 carious lesions. The mean depth and area of the lesions were $107.6 \mu \mathrm{m}$ and $1.14 \mu \mathrm{m}^{2}$, respectively. The difference in depth and area of lesions between group ICDAS 1 and ICDAS 2 was significantly statistical with $p=0.0001$. The micrographs showed that after being soaked in demineralization solution, enamel surface became rough, enamel rods lost the minerals in the body more than in the sheath, cross-sectional images showed widened gaps between the rods due to demineralization. There was a difference in demineralization degree between group ICDAS 1 and 2. Conclusion: The image of carious lesions was gained after the teeth were soaked in demineralization solution. It showed different characteristics of the resulted lesions based on ICDAS criteria for early carious lesions using scanning electron microscope.
\end{abstract}

Key words: demineralization, fluoride, $\mathrm{pH}$ cycling, remineralization, scanning electron microscopy

\section{INTRODUCTION}

The tooth enamel is one of the four major tissues that builds up the tooth. It plays an important role in functional and esthetic. It covers the outer layer of the crown and contains the highest percentage of minerals. However, tooth enamel is always exposed to a changeable and complicated oral environment, so it is at a high risk of being decayed and destroyed. ${ }^{1 .}$

Although the white spot lesion is considered as the earliest sign of tooth decay, it will progressively turn into more severe lesion. ${ }^{2}$ Before those spots become bigger and visible, it is initialized with a mineral loss in the outer micro-crystalline. The demineralization process consists of two phases. The first phase is when the enamel mineral is solubilized in acidic solution, subsequently, dissolved the mineral ions. The ions diffuse from surface to subsurface layer of the carious lesion. It goes through the environment that is rich in protein and water via the pores in the interrod and the intercrystalline enamel areas. It is believed that demineralized enamel surface is rougher than sound enamel surface. The enlargement of enamel sheath results in a way surface to subsurface layer of the carious lesion. ${ }^{1,3}$

Dental caries that is diagnosed and treated early will decrease the cost of treatment and the effectiveness will be higher. ${ }^{2}$ Study on the structure and the mechanism of the formation of early caries is an important subject for evaluating the caries-preventive methods. So far, 
Table 1. The ICDAS visual criteria for detecting carious lesions

\begin{tabular}{ll}
\hline Code & Criteria \\
\hline ICDAS 0 & Sound tooth surface \\
ICDAS 1 & $\begin{array}{l}\text { First visual change in enamel (white spot seen } \\
\text { after 5 seconds air drying) }\end{array}$ \\
ICDAS 2 & $\begin{array}{l}\text { Distinct visual change in enamel (white spot } \\
\text { seen without air drying). } \\
\text { Localized enamel breakdown due to caries }\end{array}$ \\
\hline
\end{tabular}

Table 2. Distribution of experimental early carious lesions based on ICDAS

\begin{tabular}{ccc}
\hline \multirow{2}{*}{ ICDAS } & \multicolumn{2}{c}{ Number of teeth } \\
\cline { 2 - 3 } & $\mathrm{N}$ & $\%$ \\
\hline 0 & 0 & 0 \\
1 & 40 & 66.7 \\
2 & 20 & 33.3 \\
3 & 0 & 0 \\
Total & 60 & 100 \\
\hline
\end{tabular}

although many studies of early dental caries have been performed in the some country, it remains just a few in Vietnam. Besides, there are differences in histological features and progressive process in dental caries between races, setting a demand of clarifying basic characteristics of caries lesion experimentally in Vietnamese permanent teeth.

\section{OBJECTIVE}

Basen on these above mentioned issues, we conducted the research to describe image of early experiment dental caries in permanent teeth in Ha Noi Medical University in 2014. The study aimed to describe macro and micro images of carious lesions at early stage in permanent teeth examined under a scanning electron microscope (SEM) using the ICDAS criteria for early caries detection.

\section{METHODS}

This experimental study was conducted in 60 premolars which had been collected from various dental clinics in Hanoi within a month. Those teeth had been extracted in preparation for orthodontic treatment in patients aged 18-25 with comprehensive awareness and permission from them. The remaining soft tissue was removed and the samples had been thoroughly rinsed with water, right after the tooth removal. The teeth were handled according to infection control guidelines for use of extracted teeth then steeped in storage solution thymol $0.1 \%$ at $37^{\circ} \mathrm{C}$ until being used. ${ }^{4}$ The inclusion criteria were premolars with sound tooth surface. The teeth with cracked, decayed surface (white or brown
Table 3: Depth and area of experimental early carious lesions

\begin{tabular}{llllll}
\hline & N & Mean & SD & Min & Max \\
\hline Depth $(\mu \mathrm{m})$ & 60 & 107.60 & 19.4 & 78.18 & 150.22 \\
Area $(\mu \mathrm{m} 2)$ & 60 & 1.14 & 0.2 & 0.61 & 1.57 \\
\hline
\end{tabular}

Table 4: The relationship between the depth of the early carious lesions and ICDAS criteria.

\begin{tabular}{llll}
\hline & $\begin{array}{l}\text { ICDAS 1 } \\
(\mathbf{N = 4 0 )}\end{array}$ & $\begin{array}{l}\text { ICDAS2 } \\
(\mathbf{N = 2 0 )}\end{array}$ & $\boldsymbol{p}$ \\
\hline Mean depth $\pm \mathrm{SD}(\mu \mathrm{m})$ & $100.30 \pm 18.05$ & $122.19 \pm 12.80$ & 0.0001 \\
Min & 78.18 & 97.64 & \\
Max & 142.11 & 150.22 & \\
& & & \\
Mean area $\pm \mathrm{SD}(\mu \mathrm{m} 2)$ & $1.06 \pm 0.18$ & $1.30 \pm 0.16$ & 0.0001 \\
Min & 0.61 & 0.92 & \\
Max & 1.43 & 1.57 & \\
& & & \\
\hline
\end{tabular}

spot or cavity), enamel hypoplasia, fluorosis, and/ or tetracycline stains were excluded. The study was performed at the School of Odonto-Stomatology, Hanoi Medical University and Morphology Department, Institute 69, Mausoleum Command. The value of clinical examination and parameters included the depth, the area and images of surface under the SEM and the cross-sectional section of a smooth surface carious lesions were recorded according to data collection form. Different stages of carious lesions were distinguished based on the ICDAS visual criteria for detecting carious lesions (Table 1).

Carious lesions in late stage, with visible cavity is added to the ICDAS 3. The index evaluates an area and depth of the cavity, that is calculated by photo processing software. The figures of surface and cross-section of carious lesions were observed in various campus to clearly see the image of caries lesions. The materials used were thymol $0.1 \%$, saline solution, deionized water, distilled water, tissue-paper, acid-resistant coating, (nail polish, Revlon-USA), deminalization solution $\left(2.2 \mathrm{mM} \mathrm{CaCl} ; 2.2 \mathrm{mM} \mathrm{KH}_{2} \mathrm{PO}_{4}, 50 \mathrm{mM}\right.$ lactic acid, and $0.02 \mathrm{ppm} \mathrm{F}^{-}$. The $\mathrm{pH} 4.4$ was adjusted with $1 \mathrm{M}$ $\mathrm{KOH}$. Scanning electronic microscope (JSM 5410LV, JEOL, Japan). Before being used, all the sample teeth were thoroughly rinsed with saline solution and then dried by blotting paper. Subsequently, they were painted with acid-resistant coating leaving an enamel window of approximately $1 \times 1 \mathrm{~mm}^{2}$. After the first layer was dried, we applied the second layer with the same manner then stored temporarily all the samples in saline solution in ordinary room temperature until being used. All the samples were soaked in $1200 \mathrm{ml}$ of demineralization solution at room temperature $\left(37^{\circ} \mathrm{C}\right)$ in 4 days to create the demineralized lesions. 
Subsequently, the teeth were being soaked long enough in demineralization solution (96 hours) and be checked and classified using the ICDAS criteria.

Each specimen was observed under scanning electronic microscope while it was holding on a stage. Observation and finding the suitable field were performed and a photograph of each specimen at various fields was taken. The produres aimed to document the entire demineralized lesion and the sound edges of the lesion area. Subsequently, all the photos were analyzed and processed by Image-Pro Plus software to measure depth (at the deepest site) and area of the lesions (corresponding to the size of $1 \mathrm{~mm}$ surface). The images of demineralized enamel structure was then evaluated. Each measurement was taken three times and the result was determined as the average value of the three measurements.

Data were analyzed using SPSS 17.0. The bias was controlled by having big enough sample size with selected based on given criteria. Furthermore, the diagnosis was based accurately on the ICDAS criteria for dental caries detection and the instruments for measuring were standardized and unified.

About ethical issues, this study was strictly complied with the given procedures. The results were presented in accordance with the results gained, only to be used to provide data and references for further research with commiting of being honest and not intervened by the product vendor.

\section{RESULTS}

Table 2 showed that artificially carious lesions was mainly the ICDAS 1 with $66.7 \%$, followed by the ICDAS 2 with $33.3 \%$. After being soaked in demineralization solution, there was no tooth without carious lesions or with localized enamel breakdown due to caries. Under microscope, the mean depth of experimental carious lesions was $107.60 \mu \mathrm{m}$ with the range of value was $78.18 \mu \mathrm{m}$ to $150.22 \mu \mathrm{m}$. Meanwhile, the mean area in cross-section of experimental carious lesions (associated with $1 \mu \mathrm{m}$ of the surface) was $1.14 \mu \mathrm{m}^{2}$, ranging from $0.61 \mu \mathrm{m}^{2}$ to $1.57 \mu \mathrm{m}^{2}$ (Table 3 ).

The mean depth of the ICDAS 1 group was $100.3 \mu \mathrm{m}$, the ICDAS 2 group was $122.19 \mu \mathrm{m}$. One way ANOVA Test showed that the difference of area between 2 groups was statistically significant with $p=0.0001$ (Table 4). Mean area of group ICDAS 1 was $1.06 \mu \mathrm{m}^{2}$, group ICDAS 2 was $1.30 \mu \mathrm{m}^{2}$. One way ANOVA Test showed that the difference of area between 2 groups was significantly with $p=0.0001$ (Table 4).

\section{DISCUSSION}

The process of remineralization and demineralization was a very balance sensitive process. A small change in the $\mathrm{pH}$ levels could lead to an imbalance of enamel mineralization. This study showed an experimental model of early stages carious lesions. The teeth were soaked in a solution containing lactic acid $50 \mathrm{mM}$, $\mathrm{CaCl}_{2} 2.2 \mathrm{mM}, \mathrm{KH}_{2} \mathrm{PO}_{4}: 2.2 \mathrm{mM}$, ion $\mathrm{F}^{-}: 0.02 \mathrm{ppm}$ at $\mathrm{pH}=4.4$ adjusted with $1 \mathrm{M} \mathrm{KOH}$. With the majority of the early stages of tooth decay, we also used this solution to create demineralized lesions. ${ }^{5,6}$ Lactic acid was often used to create artificially carious lesions in human enamel because in fact, it accounted for $90 \%$ acid product of the sucrose or glucose metabolism by Streptococcus bacteria in the oral environment. ${ }^{6}$ To create lesions similar to natural decay, the $\mathrm{Ca}^{2+}, \mathrm{PO}_{4}^{2}$, $\mathrm{F}^{-}$ion were added to the demineralization solution. These were protective factors of the surface layer of enamel. The proper amount was used to create a slight damage in the surface layer and dissolved mineral ions could diffused from surface to subsurface layer. Some authors only used acidic solution to damage the early stages of tooth decay, but without the protective factors, the lesions created were similar to erosion lesions than caries. ${ }^{3,6}$

There are many ways to evaluate the loss of enamel minerals such as visual examination, X-ray, hardness measurement of enamel surface, using polarized light, using fluorescent light of DIAGNOdent laser, observations under SEM. ${ }^{7}$ This study used the ICDAS visual criteria for detecting caries lesions and observed under a scanning electronic microscope SEM.

With the evaluation based on the ICDAS criteria, after being soaked for 96 hours, the created lesion would be visually examined and the results were: $66.7 \%$ was ICDAS stage $1,33.7 \%$ was ICDAS 2 . The lesions obtained mainly in the early stages. Being soaked in the same solution at the same conditions but the level of lesion varied, there were lesions at ICDAS stage 1 , but there were also ICDAS 2 lesions, may be due to the difference between structure of each individual enamel against the attack of acids that caused dental caries. Thus, in demineralization solution with $\mathrm{pH}$ $=4.4$, the destruction of enamel mineral were more dominant than the remineralization, leading to form demineralized lesions. Those lesions were similar to early stages carious lesions, appeared when $\mathrm{pH}$ level in the oral environment lowered because of organic acids from bacterial metabolism of carbohydrates from food, while the concentration of $\mathrm{F}^{-}$in the mouth was not enough to prevent mineral dissolve. 
The micrographs of the experimental teeth observed under the SEM were shown in Figures 1-15.

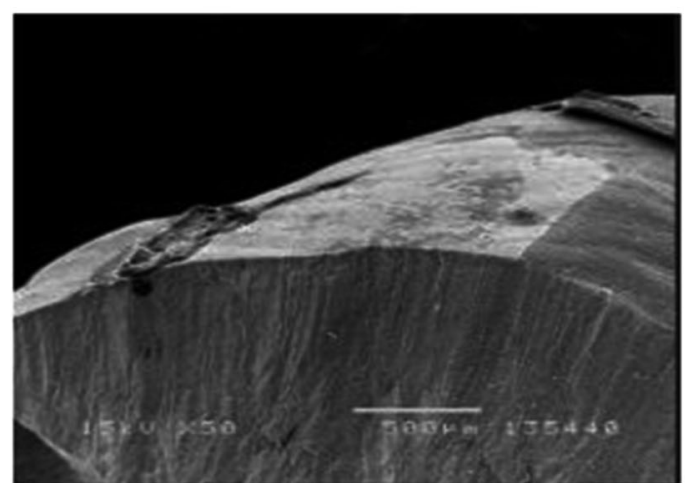

Figure 1. Micrograph of enamel window in our study

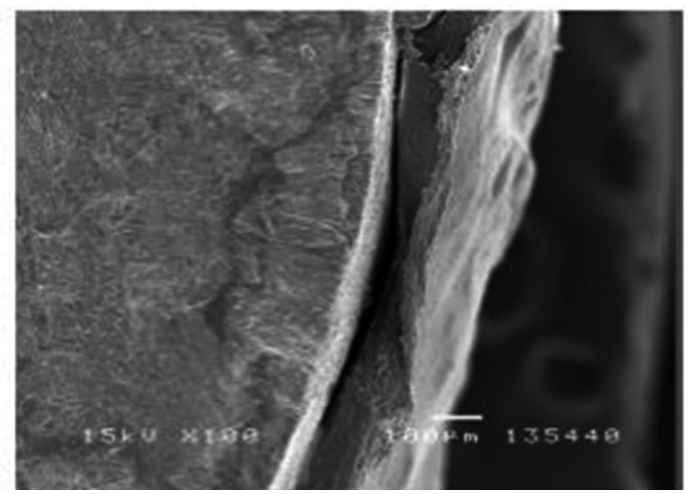

Figure 2. Structure of dental caries at early stage

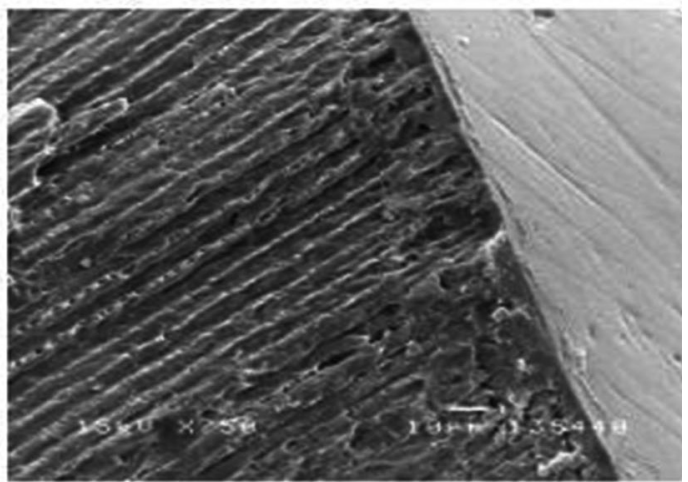

Figure 3. Sound enamel

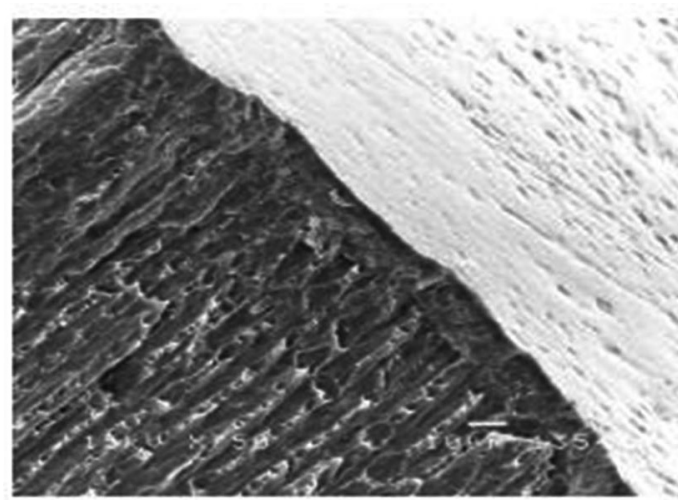

Figure 4. Enamel surface after being demineralized

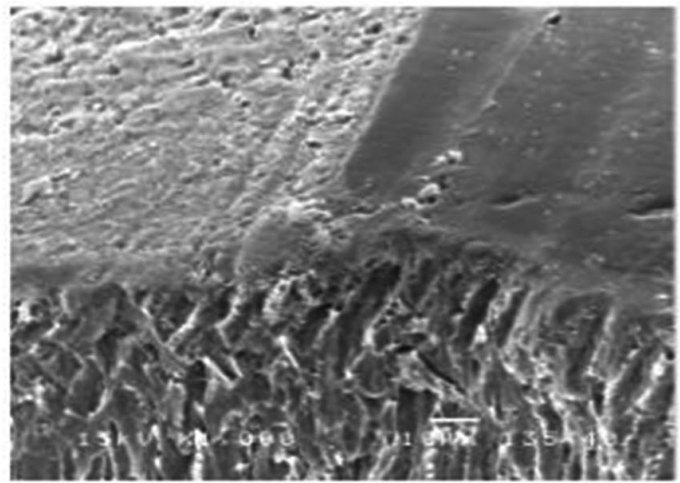

Figure 5. Border between sound and demineralized enamel surfaces

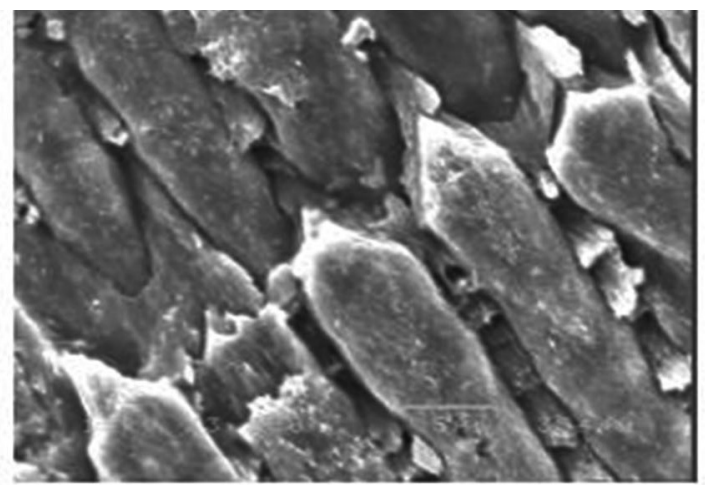

Figure 6. Normal enamel rods

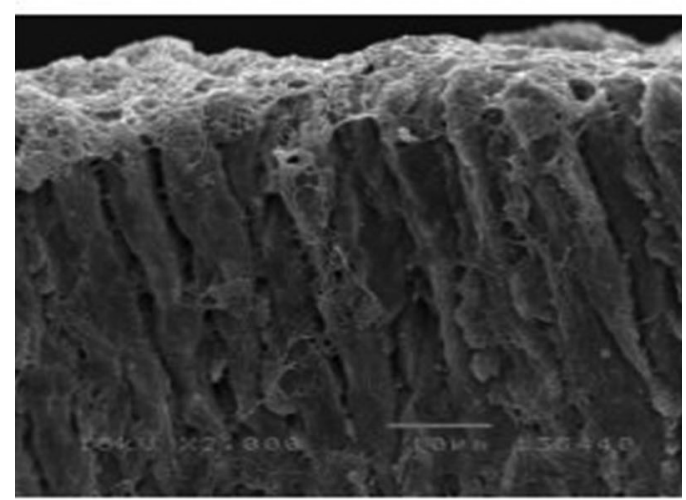

Figure 7. Enamel rods after being demineralized

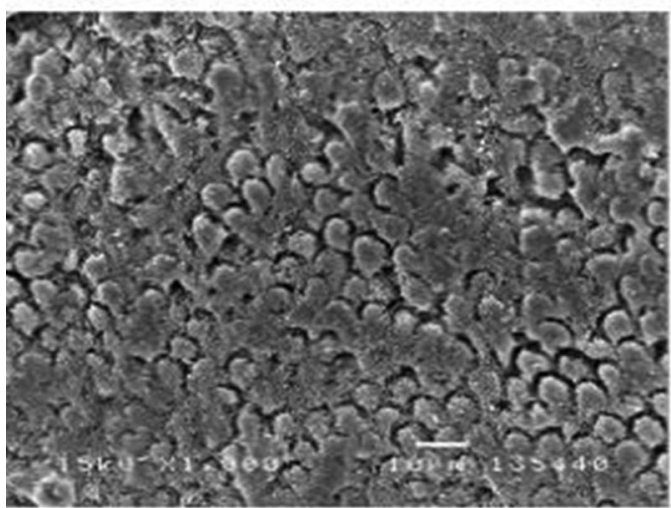

Figure 8. Demineralized enamel surface on the ICDAS 1 group 


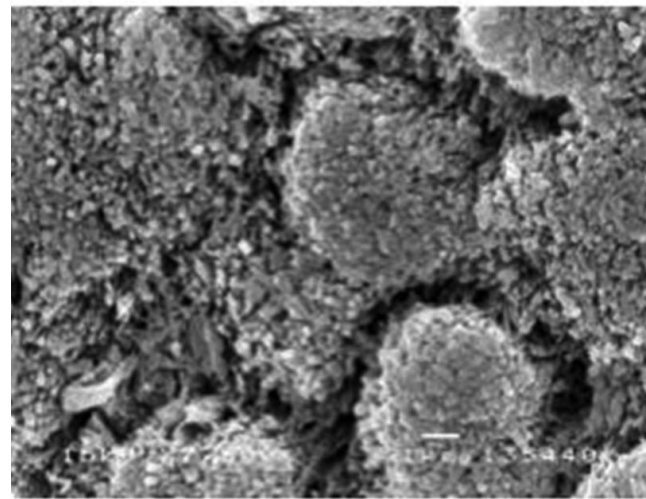

Figure 9. Peripheral enamel crystals were dissolved, forming gaps around crystals in the centre on the ICDAS 1 group

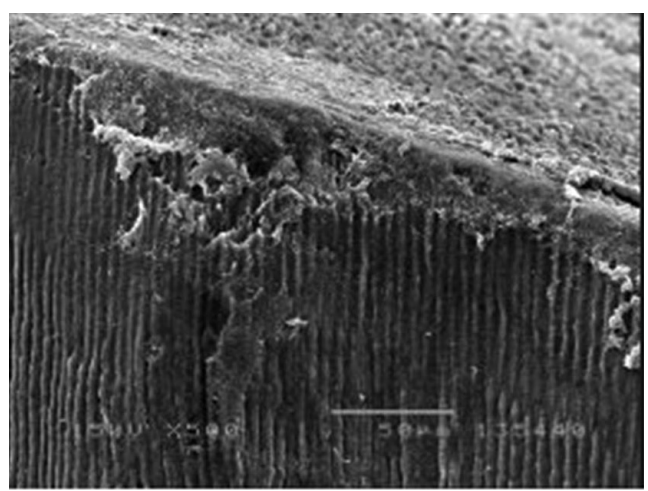

Figure 10. Mineral layer covered the lesion surface, enamel rod diameters appeared quite uniform on the ICDAS 1 group

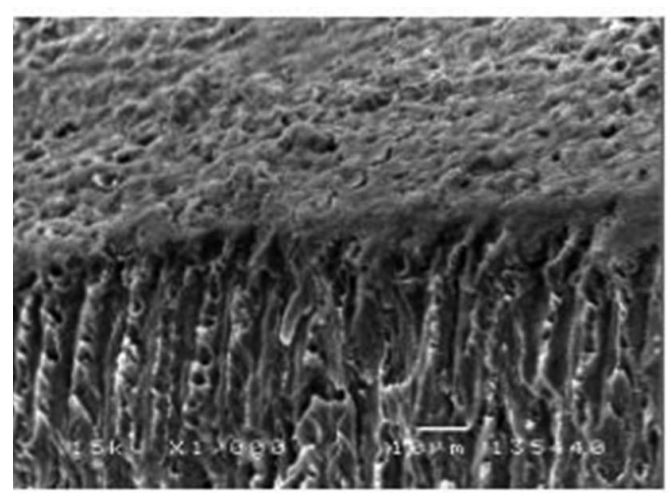

Figure 11. Many cavities appeared in the surface layer of the lesion and in enamel rods in crosssectional surface on the ICDAS 1 group

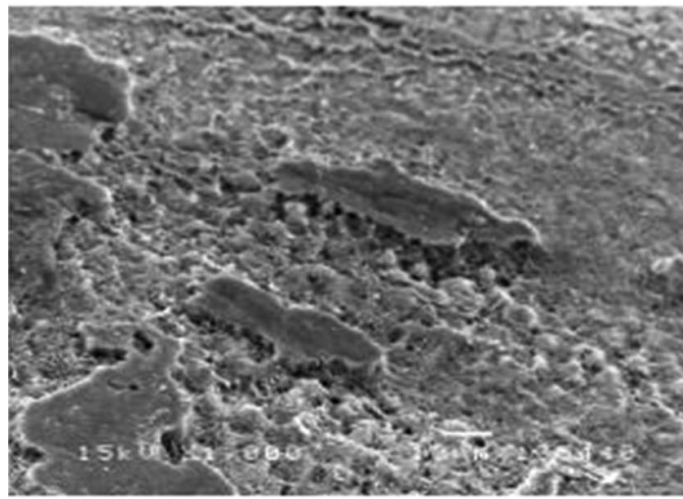

Figure 12. Demineralized enamel surface on the ICDAS 2 group

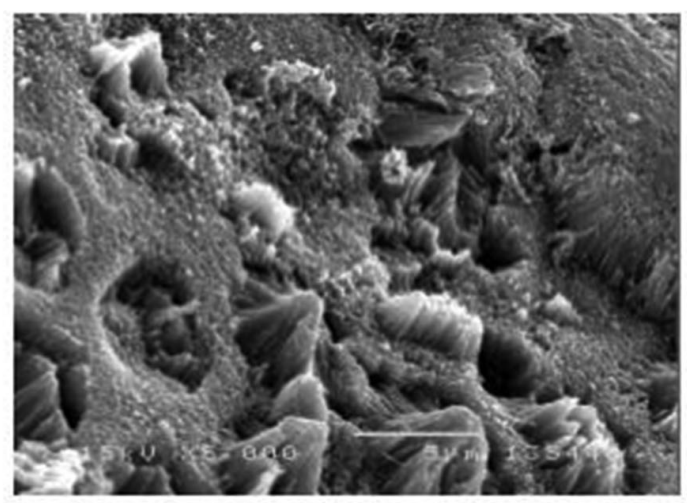

Figure 13. Demineralization process of enamel rods formed many cavities on the ICDAS 2 group

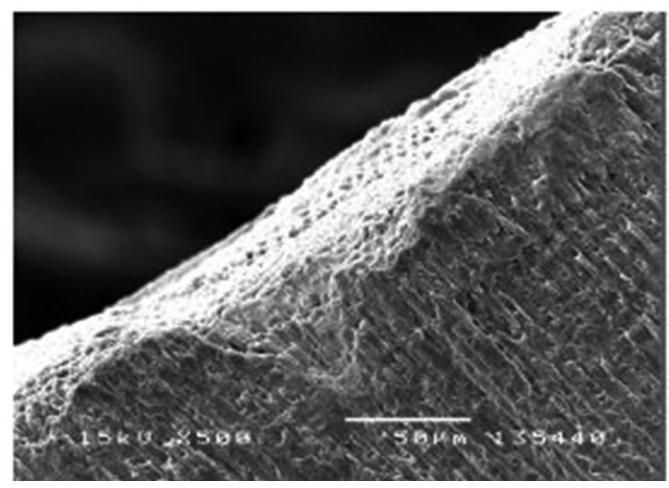

Figure 14. Mineral layer covered the lesion surface was not clear, enamel rod diameters were not uniform on the ICDAS 2 group

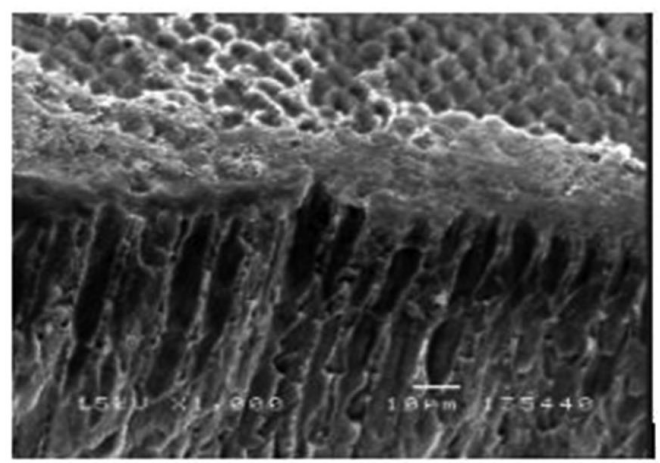

Figure 15. Demineralization process of enamel rod formed many cavities in surface and enamel rods in in the cross-section on the ICDAS 2 group 
About the depth and size of lesions in the early stages of tooth decay experiments, the average depth was $107.6 \mu \mathrm{m}$, the average area was $1.14 \mu \mathrm{m}^{2}$. This result was consistent with the finding of other authors using the same demineralization solution to create the experimental early stages caries lesions. ${ }^{5}$ The depth and the area of the lesions were not too high but it was enough to be able to see with the naked eye. If a lesion was detected when blowing teeth in 5 seconds, then the level of destruction was small, if lesions were detected even when the surface was still wet, the degree of tooth mineralization was of greater destruction. Table 4 compared the depth and area of lesions in the group ICDAS 1 and 2, the results showed that the difference in the depth and area between the two groups were clearly statistically significant.

The transparency of the enamel surface was an optical phenomenon, it depended on the size of the interrod spaces. In the early stage caries, white spot lesions could be detected only if it appeared after 5 seconds air drying, due to the disolution of peripheral crystal of enamel rod. At a later stage, with the expansion of the gap between enamel crystals, and the widened interrod spaces also led to white spot lesions that could be seen when the surface was still wet. Effect of dehydration on the state of enamel's transparency due to surrounding evironment of enamel rod was replaced by air instead of liquid environment. It was the scattering effect in a heterogeneous system where each component had different refractive indices, such as the refractive index of water was 1.33 , of air was 1.00 , while of the enamel was 1.65 . The difference was too high in refractive index led to the scattering of light between men and atmosphere. ${ }^{8,9}$

Research on SEM images of allowed evaluation of demineralization by observing the morphology and the characteristics of enamel structure such as morphology, the diameter of the enamel rods, sound and demineralized enamel surface morphology. ${ }^{10}$ The normal enamel surface was sound and not showing rough appearance. The enamel surfaces and boundary between rods could not be clearly seen. After being soaked in a demineralization solution, enamel surface became rough, not smooth (Figure 3, Figure 5). The enamel crystals dissolved in an acid environment, leaving many cavities on the surface, the peripheral crystals tended to be dissolved more easily than the center of the crystal. This was the path for acid to diffuse through the surface to subsurface layer, forming demineralized lesion. Cross-sectional micrograph showed the structure of the lesion was a cone shaped cavity, with the base towards the tooth surface (Figure 2). This was also consistent with the findings of several authors on the study of white spot lesions on natural teeth. ${ }^{11,12}$ Comparing the changes in surfaces as well as cross-sections in groups 1 and 2 ICDAS showed the level of damage in two groups differed clearly. In group ICDAS 1, on the enamel surface,there were widened gaps between enamel rods, cross-sectional images showed enamel rods shrunk in size (Figure $8-11$ ), while in group ICDAS 2 (Figure 12-15), on the enamel surface there were images of worn enamel surface, leaving lesion layer underneath, losing more mineral in the body than than in the sheath of enamel rods. Cross-sectional images showed that enamel rods shrunk in size, leading to widen gaps between enamel rods. ${ }^{13}$

\section{CONCLUSION}

This study had successfully create a experimental model of early artificial carious lesion and had classified the lesion according to the ICDAS and characterized the differences the between the ICDAS 1 to ICDAS 2 using SEM.

\section{ACKNOWLEDGMENT}

The authors wish to thank the Staff of School of Odonto - Stomatology, Hanoi Medical University and Morphology Department, Institute 69, Mausoleum Command for their support in this study.

\section{REFERENCES}

1. Robinson C, Shore RC, Brookes SJ, Strafford S, Wood SR, Kirkham J. The chemistry of enamel caries. Crit Rev Oral Biol Med. 2000;11:481-95.

2. Featherstone JD. Caries prevention and reversal based on the caries balance. Pediatr Dent. 2006;28:128-32.

3. Hayasi O, Chiba T, Shimoda S, Momoi Y. Demineralization and remineralization phenomena of human enamel in acid erosion model. J Hard Tissue Biol. 2016;25:27-34.

4. Lolayekar NV, Bhat V, Bhat S. Disinfection method of extracted human teeth. J Oral Health Comm Dent. 2007;1:27-9.

5. Hegde MN, Moany A. Remineralization of enamel subsurface lesions with casein phosphopeptideamorphous calcium phosphate: A quantitative energy dispersive X-ray analysis using scanning electron microscopy: an in vitro study. J Conserv Dent. 2012;15:61-7.

6. Buzalaf MA, Hannas AR, Magalhães AC, Rios D, Honório HM, Delbem AC. pH-cycling models for in vitro evaluation of the efficacy of fluoridated dentifrices for caries control: strengths and 
limitations. J Appl Oral Sci. 2010;18:316-34.

7. Pretty IA. Caries detection and diagnosis: novel technologies. J Dent. 2006;34:727-39.

8. Meng Z, Yao XS, Yao H, Liang Y, Liu T, Li Y, Wang G, Lan S. Measurement of the refractive index of human teeth by optical coherence tomography. J Biomed Opt. 2009;14:034010.

9. Yu B, Ahn JS, Lee YK. Measurement of translucency of tooth enamel and dentin. Acta Odontol Scand. 2009;67:57-64.

10. de Marsillac Mde W, Vieira Rde S. Assesment of artificial caries lesions through scanning electron microscopy and cross-sectional microhardness test. Indian J Dent Res. 2013 Mar-Apr;24:249-54.

11. Haikel Y, Frank RM, Voegel JC. Scanning electron microscopy of the human enamel surface layer of incipient carious lesions. Caries Res. 1983;17:1-13.

12. Frank RM. Structural events in the caries process in enamel, cementum and dentin. J Dent Res. 1990;69:559-66.

13. Hung HT, Tram HDB. Tác dụng của ACFP và verni có Fluor trên men răng và khử khoáng thực nghiệm. Tạp chí Y dược thành phố Hồ Chí Minh. 2007;3:15-19. Vietnamese.

(Received December 15, 2015; Accepted April 5, 2016) 